\title{
CONTRADIÇÕES DA POLÍTICA AMBIENTAL POR MEIO DE INCENTIVOS FINANCEIROS: OS CASOS DO ICMS ECOLÓGICO E DA CFEM NOS MUNICÍPIOS DO QUADRILÁTERO FERRÍFERO (MINAS GERAIS, BRASIL) ${ }^{1}$
}

\author{
Ana Carolina Pinheiro Euclydes ${ }^{2}$
}

\begin{abstract}
RESUMO - A partir do levantamento dos valores recebidos pelos municípios situados na região do Quadrilátero Ferrífero, em Minas Gerais, em decorrência do ICMS Ecológico, repassado pelo Estado e da Compensação Financeira pela Exploração de Recursos Minerais (CFEM) recebida da União, este artigo relativiza o potencial do ICMS Ecológico para incentivar os municípios mineradores a criarem ou apoiarem unidades de conservação (UCs) em seus territórios. Nesta discussão, trazem-se à tona avaliações técnicas e acadêmicas sobre a qualidade da proteção ambiental realizada nas UCs ali situadas e destacam-se os conflitos de interesses entre a mineração e a proteção ambiental na região. Por fim, conclui ser necessário aprimorar o ICMS Ecológico em Minas Gerais e propõem-se medidas para tornar a conservação ambiental mais interessante economicamente para os municípios.
\end{abstract}

Palavras-chave: Unidade de conservação; ICMS Ecológico; CFEM.

\section{CONTRADICTIONS OF THE ENVIRONMENTAL POLICY THROUGH FINANCIAL INCENTIVES: THE CASES OF THE ICMS ECOLÓGICO AND THE CFEM IN THE MUNICIPALITIES OF THE QUADRILÁTERO FERRÍFERO REGION (MINAS GERAIS, BRAZIL)}

\begin{abstract}
From the survey on the values received by the municipalities located in the Quadrilátero Ferrífero region in the state of Minas Gerais due to the ICMS Ecológico (a modality of the Brazilian value added tax which's revenues are distributed by states acording to environmental criteria) and to the Financial Compensation for Exploitation of Mineral Resources received from the Federal Government, the objective of this study is to relativize the potential of the ICMS Ecológico to encourage municipalities to establish or to support protected areas (PAs) in their territories. This discussion brings about academic and technical evaluations of the quality of environmental protection held in the PAs situated there and highlights the conflicts of interest between mining and environmental protection in the region. Finally, it concludes that it is necessary to improve the ICMS Ecológico in Minas Gerais and proposes measures to make conservation more economically interesting to municipalities.
\end{abstract}

Keywords: Protected areas; ICMS Ecológico; CFEM.

\section{INTRODUÇÃO}

A política ambiental brasileira se fundamenta em dois tipos de mecanismos: o conhecido como "comando e controle" e os instrumentos econômicos de gestão. Por mecanismos de "comando e controle" entende-se o conjunto de regras definidas para o uso dos recursos ambientais, o estabelecimento de padrões de emissão de poluentes para fontes específicas, a concessão de licenças para atividades potencialmente poluentes, $o$ controle de equipamentos, processos, insumos, produtos, entre outros. Já os instrumentos econômicos relacionados à política ambiental se referem a práticas como a instituição de tributos referentes aos impactos ambientais ou a criação de incentivos fiscais para estimular o empreendedor a tomar medidas ambientalmente adequadas.

\footnotetext{
${ }^{1}$ Recebido em 23.02.2011. aceito para publicação em 06.11.2013.

${ }^{2}$ Universidade Federal de Minas Gerais. E-mail:<anacpeuclydes@gmail.com>.
} 
No âmbito da política ambiental do Estado de Minas Gerais, como em todo o país, preponderam os mecanismos de comando e controle, como os previstos pela Lei Florestal mineira, Lei Estadual n 14.309 , de 2002, pelas diferentes normas de criação de áreas protegidas ou pela Deliberação Normativa n ${ }^{\circ}$ 74, de 2004, do Conselho Estadual de Política Ambiental (COPAM), que define critérios para o licenciamento ambiental.

Mas há também importantes iniciativas no rol dos instrumentos econômicos. Como exemplos, podem-se citar o benefício Bolsa Verde, instituído pela Lei Estadual $n^{\circ} 17.727$, de 2008, que prevê a concessão de um incentivo financeiro aos proprietários e posseiros que já preservam ou que se comprometam a recuperar a vegetação de origem nativa em suas propriedades ou posses, e o ICMS $^{3}$ Ecológico, originado da Lei Estadual n ${ }^{\circ} 12.040$, de 1995. Essa lei disciplinou a distribuição dos recursos arrecadados pelo estado com esse imposto, que integram a cota-parte dos municípios, incorporando temas ambientais aos critérios de distribuição. Atualmente, o ICMS Ecológico mineiro contempla os municípios que possuem unidades de conservação (UCs) ou fragmentos de mata seca em seus territórios ou que realizam tratamento e disposição final adequada de lixo ou esgoto.

O ICMS Ecológico é um instrumento amplamente difundido no país. Instituído originalmente pelo Estado do Paraná, em 1991, disseminou-se rapidamente, de modo que, em 2002, nove outros estados brasileiros já haviam seguido o exemplo paranaense, aprovando legislações similares (LOUREIRO, 2002).

Para Bensusan (2002), há duas funções principais no repasse do ICMS Ecológico aos municípios que possuem UCs. A primeira é a compensação pela arrecadação que o município deixa de realizar em função das restrições ao uso da área destinada à proteção ambiental, e a segunda consiste no incentivo financeiro para a criação e ampliação do número de UCs e melhoria da qualidade da proteção destas. Porém, há críticas ao instrumento. Ainda que a legislação mineira preveja a avaliação periódica da qualidade da proteção ambiental nas UCs - cujos resultados repercutem nos valores a serem repassados aos municípios -, não existe vinculação dos recursos obtidos por meio do ICMS
Ecológico à proteção ambiental. Assim, um município pode receber repasses do imposto estadual por uma área protegida sem atuar ativamente para sua proteção.

Outra crítica ao instrumento se refere à limitação da função incentivadora do ICMS Ecológico. A crítica se deve à variação significativa dos valores dos repasses conforme a categoria e a área da UC e ao fato de que, muitas vezes, tais valores não resultam economicamente interessantes para os municípios. Nesses casos, o investimento na criação de UCs se torna uma alternativa de retorno econômico restrito, especialmente quando o município possui reservas minerais valiosas. Isso porque os municípios mineradores recebem, além dos repasses de ICMS por meio do critério "município minerador”, a Compensação Financeira pela Exploração de Recursos Minerais (CFEM), cujos valores são extraordinariamente mais expressivos que os do ICMS Ecológico", no caso de municípios produtores de substâncias como o ferro e o ouro. São casos comuns na região central de Minas Gerais, onde se localiza o Quadrilátero Ferrífero, uma das mais expressivas províncias minerais do mundo, e onde se situa a maior concentração de áreas protegidas do estado.

Tendo em vista essa situação, este artigo objetiva discutir aspectos do ICMS, da CFEM e da criação de UCs no estado, a partir do estudo dos casos dos municípios situados no Quadrilátero Ferrífero.

\section{MATERIAL E MÉTODOS}

Este artigo foi elaborado a partir de revisão bibliográfica. Para desenvolvê-lo, recorreu-se às normas que disciplinam o ICMS, em Minas Gerais, e a CFEM, em âmbito nacional. Além disso, levantou-se o histórico da ocupação da porção sul da Região Metropolitana de Belo Horizonte (RMBH) e da criação de áreas destinadas à proteção ambiental nessa região.

Para proceder às comparações entre os valores recebidos pelo ICMS e pela CFEM, buscou-se a relação dos municípios localizados no Quadrilátero Ferrífero adotada pelo Centro de Estudos Avançados do Quadrilátero Ferrífero(UFOP, 2010). Diante dessa relação, recorreu-se aos dados da Fundação João Pinheiro (FJP) referentes às transferências do ICMS pertinentes aos municípios e aos do Departamento Nacional de Produção

\footnotetext{
${ }^{3}$ Imposto sobre Operações Relativas à Circulação de Mercadorias e sobre Prestações de Serviços de Transporte Interestadual e Intermunicipal e de Comunicação.
} 
Mineral (DNPM) relativos aos repasses da CFEM. Os dados do ICMS foram apurados para os critérios “município minerador" e "meio ambiente”, sendo esse último discriminado também no subcritério "unidades de conservação”.

Por fim, visando avaliar a qualidade da proteção ambiental realizada nas UCs situadas nos municípios que recebem os maiores valores em CFEM no Quadrilátero Ferrífero, foram consultados a Resolução da Secretaria de Estado de Meio Ambiente e Desenvolvimento Sustentável (SEMAD) n 1004, de 2009, que divulga pontuação do Fator de Qualidade referente às UCs, e o estudo de Lima et al. (2005), sobre a efetividade das UCs de proteção integral no estado.

\section{RESULTADOS}

\subsection{O repasse do ICMS em Minas Gerais: critérios}

O ICMS é um imposto suportado pelo consumidor, na medida em que este realiza seu consumo de mercadorias e serviços. Ele é arrecadado pelo estado e dividido entre este (75\%) e os municípios (25\%), conforme estabelecido pelo art. 158 da Constituição da República. Também segundo disposição constitucional, desses $25 \%$ que devem ser repassados aos municípios, o mínimo de 75\% deve ser distribuído segundo o valor adicionado fiscal $\left(\mathrm{VAF}^{4}\right)$, sendo a distribuição do restante passível de definição pelos estados (BRASIL, 1988).

Até 1995, Minas Gerais repassava o ICMS segundo os critérios VAF (94,39\%) e produção minerária (5,61\%) (MINAS GERAIS, 1991). A partir de janeiro de 1996, com a vigência da norma conhecida como Lei Robin Hood $^{5}$, o estado acrescentou a esses critérios outros relacionados a: área geográfica, saúde, educação, área cultivada, patrimônio cultural, receita própria, população, cota mínima e meio ambiente (MINAS GERAIS, 1995). Na última versão dessa norma - Lei Estadual no 18.030, de 2009 -, foram acrescidos ainda critérios relativos a: porção do território municipal alagada por reservatório destinado à produção de energia, sede de estabelecimento penitenciário, esportes, turismo, ICMS solidário e mínimo "per capita".
Mesmo com essas mudanças, permaneceu vigendo o critério "município minerador" - antigo "produção minerária”. Esse critério consiste na percentagem média do Imposto Único sobre Minerais (IUM) recebido pelos municípios mineradores em 1988, com base em índice elaborado pela Secretaria de Estado da Fazenda, demonstrando a efetiva participação de cada um na arrecadação do IUM naquele exercício. Em 1995, a participação desse critério no total dos repasses do ICMS foi reduzida de 5,61 para $1,5 \%$, sendo progressivamente diminuída até 1998, quando se fixou em $0,11 \%$. Em 2011, esse percentual passou a 0,01.

Mesmo se tratando de um critério defasado - muitos municípios que hoje têm suas economias fortemente relacionadas às atividades extrativas minerais não tinham essas características em 1988 -, sua permanência entre os temas da Lei Robin Hood atesta a valorização da produção mineral, em contraste com a proteção ambiental pretendida pelo ICMS Ecológico, conforme veremos.

Na versão mais recente da Lei Robin Hood, o critério meio ambiente sofreu modificações, vigentes a partir de 2011. Então, o ICMS Ecológico passou a corresponder a $1,1 \%$, e não mais a $1 \%$, do ICMS repassado aos municípios, sendo que a ocorrência de mata seca no território municipal foi incorporada como mais um subcritério, correspondendo a 9,1\% dos 1,1\%, enquanto os subcritérios unidades de conservação e saneamento ambiental passaram a responder por $45,45 \%$ dos 1,1\% cada (MINAS GERAIS, 2009a).

No que se refere especificamente ao subcritério relacionado às UCs, o valor do repasse por área protegida é obtido por meio da multiplicação da razão entre a área da UC e a área do município pelo Fator de Conservação atribuído à categoria da UC e pelo Fator de Qualidade conferido a essa UC. O Fator de Conservação é mais elevado para as categorias que implicam maiores restrições ao uso, como as estações ecológicas e as reservas biológicas, e menos expressivos para as UCs de categorias mais flexíveis, especialmente as desprovidas de zoneamento ecológico-econômico (ZEE). Já o Fator de Qualidade corresponde à avaliação

\footnotetext{
${ }^{4}$ O VAF reflete o movimento econômico de cada município: corresponde à diferença entre o valor das operações de saída de mercadorias - acrescido do valor das prestações de serviços de transporte e de comunicação - e o valor das operações de entrada de mercadorias, em determinado ano civil.

${ }^{5}$ Lei n ${ }^{\circ} 12.040$, de 28 de dezembro de 1995. Dispõe sobre a distribuição da parcela de receita do produto da arrecadação do ICMS pertencente aos municípios, de que trata o inciso II do parágrafo único do artigo 158 da Constituição Federal, e dá outras providências.
} 
da UC no que se refere à efetividade da proteção ambiental que ocorre na área, sendo tanto maior quanto mais efetiva for considerada tal proteção.

Assim, esses valores estão sujeitos a grandes variações, sendo, em muitos casos, pouco expressivos economicamente. Para exemplificar os repasses por UCs e pelo critério afeto à atividade minerária, apresentam-se, na Tabela 1, os valores recebidos pelo Município de Nova Lima, referentes aos critérios “meio ambiente”/UCs e “município minerador”, no primeiro semestre de 2010. Os valores do critério relativo ao meio ambiente estão discriminados por área protegida para que se note a variação dos montantes conforme a extensão das UCs e as categorias de manejo.

Como se observa, os repasses mensais por UC em Nova Lima variam de pouco mais de R \$7, caso da Reserva Particular do Patrimônio Natural (RPPN) Feixos, até cerca de R\$3,5 mil, como no caso da RPPN Mata do Jambreiro. Além disso, nota-se que os recebimentos do município pelo critério “município minerador” são expressivamente maiores que os pagos pelas UCs. Nessa situação, que ocorre frequentemente nos municípios do Quadrilátero Ferrífero, o incentivo do ICMS Ecológico relativo às UC é sobrepujado pelo critério pertinente à mineração.

Mas a situação é ainda mais complexa. É que esses municípios mineradores recebem, além dos repasses do ICMS referentes ao critério “município minerador”, outros recursos muito mais expressivos: os provenientes da CFEM.

\subsection{CFEM}

O art. 20 da Constituição da República de 1988 define que a União, os estados, o Distrito Federal e os municípios devem receber participação no resultado da exploração de recursos minerais em seus territórios. Desse modo, cumpre às mineradoras o pagamento da compensação ao DNPM, órgão administrador da CFEM, relativa à saída por venda do produto mineral das áreas da jazida ou à utilização, à transformação industrial do produto mineral ou mesmo ao seu consumo por parte da mineradora.

As alíquotas aplicadas sobre o faturamento líquido da atividade mineral variam de acordo com a substância. Para minério de alumínio, manganês, sal-gema e potássio, aplica-se a alíquota de 3\%; já para ferro, fertilizantes e carvão, a alíquota é de $2 \%$; para o ouro, $1 \%$; e para pedras preciosas, pedras coradas lapidáveis, carbonados e metais nobres, $0,2 \%$.

Dos recursos relativos à CFEM, $12 \%$ são distribuídos para os órgãos da União, 23\% para o estado onde for extraída a substância mineral e 65\% para os municípios produtores, proporcionalmente à produção realizada em cada um deles (BRASIL, 1990). Os repasses são mensais e não podem ser aplicados em pagamento de dívida ou no quadro permanente de pessoal. O objetivo é que essas receitas sejam aplicadas em projetos que, direta ou indiretamente, revertam em prol da comunidade local, na forma de melhoria da infraestrutura, da qualidade ambiental, da saúde e da educação.

Tabela 1 - Arrecadação relativa aos critérios “meio ambiente”, referente às unidades de conservação e ao “município minerador”, do Município de Nova Lima, entre janeiro e junho de 2010.

Table 1 - Tax collection regarding the criteria "environment", referring to protected areas, and "mining town" by the municipality of Nova Lima, from January to June, 2010.

\begin{tabular}{|c|c|c|c|c|c|c|c|c|}
\hline Unidade de conservação* & Área (ha) & Jan. & Fev. & Mar. & Abr. & Maio & Jun. & Total \\
\hline APAE Sul RMBH & 39.893,9 & 391,7 & 355,2 & 388,9 & 402,9 & 388,3 & 427,9 & $2.355,1$ \\
\hline APE Fechos & 476 & 187,0 & 169,5 & 185,6 & 192,3 & 185,3 & 204,2 & $1.124,0$ \\
\hline EE Fechos & 603 & $1.421,0$ & $1.288,7$ & $1.410,8$ & $1.461,6$ & $1.408,8$ & $1.552,4$ & $8.543,2$ \\
\hline RPPNF Feixos & 2,1 & 7,4 & 6,7 & 7,4 & 7,6 & 7,4 & 8,1 & 44,6 \\
\hline RPPNE Mata do Jambreiro & 912 & $3.223,9$ & $2.923,5$ & $3.200,6$ & $3.316,0$ & $3.196,0$ & $3.521,8$ & $19.381,7$ \\
\hline RPNNE Mata Samuel de Paula & 147,8 & 522,6 & 473,9 & 518,8 & 537,5 & 518,1 & 570,9 & $3.141,7$ \\
\hline APE Mutuca & 250 & 98,2 & 89,0 & 97,5 & 101,0 & 97,3 & 107,3 & 590,3 \\
\hline PAQE Serra do Rola Moça & 774 & $1.641,6$ & $1.488,7$ & $1.629,8$ & $1.688,5$ & $1.627,4$ & $1.793,3$ & $9.869,4$ \\
\hline ICMS Ecológico/ UCs & & & & & & & & $45.049,9$ \\
\hline ICMS - município minerador & & $43.279,0$ & $39.220,2$ & 42.938,1 & 44.936,3 & $43.310,3$ & $47.696,4$ & $261.380,3$ \\
\hline
\end{tabular}

Fonte: FJP, 2010. 
Considerando as alíquotas referentes ao ferro, o vulto da produção realizada no Quadrilátero Ferrífero e os preços internacionais do produto, pode-se conceber as grandezas dos valores da CFEM que os municípios ali situados recebem. Para exemplificar, apresenta-se, na Tabela 2, a arrecadação dessa compensação realizada pelo Município de Mariana, no primeiro semestre de 2010.

Como se nota, os valores relativos ao ferro e ao minério de ferro são muito significativos. São maiores, inclusive, que as arrecadações totais de muitos municípios mineiros. Para se ter ideia, municípios vizinhos a Mariana que não se dedicam à mineração têm arrecadações totais até 50 vezes inferiores à CFEM que tal município recebe ${ }^{6}$.

Diante dessa discrepância de valores, cabe analisar mais detidamente a situação das arrecadações dos municípios situados no Quadrilátero Ferrífero.

\subsection{Quadrilátero Ferrífero: o foco das tensões}

O Quadrilátero Ferrífero constitui uma das mais expressivas províncias minerais do mundo, de onde se extraem minério de ferro, ouro e manganês, entre outros minerais (BRANDT, 2008). Estimativas do início dos anos 2000 apontam uma exploração média anual de mais de 55 milhões de toneladas de minério. Em 2007, a produção brasileira de ferro alcançou 354,67 milhões de toneladas, sendo $72 \%$ desse montante oriundo do Quadrilátero Ferrífero (UFOP, 2010).

Em função das especificidades da geomorfologia da região, com suas elevadas altitudes e formações ferríferas, ali se desenvolvem ecossistemas muito peculiares, com alta incidência de espécies endêmicas, sendo considerados de importância biológica máxima (COSTA et al., 1998). Essas características também favorecem a formação de mananciais superficiais e subterrâneos, que são de grande importância para o abastecimento metropolitano de água.

A ocupação contemporânea da região remonta ao fim do século XVII, quando ali chegaram os primeiros bandeirantes em busca de ouro. Do período colonial até meados do século $\mathrm{XX}$, o uso do solo na região esteve focado principalmente na mineração do ouro e na atividade agrícola. Por volta da década de 1950, nas proximidades da capital mineira, começaram a ser implantados loteamentos de classe média destinados a residências secundárias e alguns loteamentos populares, tendo a atividade imobiliária se intensificado significativamente entre as décadas de 1970 e 1990. A partir dos anos 1990, com o adensamento das áreas urbanas ao sul da capital, as residências secundárias foram progressivamente convertidas em moradias principais, conformando os chamados condomínios, e novos empreendimentos foram lançados, com um apelo especial ligado à ideia do contato com a natureza (FREITAS, 2004).

Essa ocupação, relacionada à urbanização e à exploração mineral do ferro, iniciada em meados do século XX, repercutiu também em progressiva degradação ambiental, relacionada a ações de desmatamento, detonação de explosivos, impermeabilização do solo, intensificação de processos erosivos, assoreamento, produção e disposição de lixo, geração e lançamento inadequado de esgotos, entre outros. Em resposta a esses impactos negativos ao meio ambiente, nas últimas décadas, várias áreas foram destinadas à proteção ambiental.

A história da constituição dessas áreas destinadas à proteção ambiental teve início na década de 1980, quando, observando o avanço da mineração e da urbanização, a empresa de saneamento da capital, algumas associações surgidas entre moradores dos condomínios e o estado empreenderam iniciativas pela

Tabela 2 - Arrecadação da CFEM pelo Município de Mariana, entre janeiro e junho de 2010. Table 2 - Collection of CFEM by the municipality of Mariana, from January to June, 2010.

\begin{tabular}{|c|c|c|c|c|c|c|}
\hline Substância & Jan. & Fev. & Mar. & Abr. & Jun. & Total \\
\hline Esteatito & 210,88 & 628,29 & 522,96 & 677,94 & $1.431,34$ & 623,69 \\
\hline Ferro & $1.138 .175,92$ & $1.622 .451,74$ & $1.195 .736,98$ & $1.248 .710,39$ & $1.365 .589,55$ & $2.103 .412,75$ \\
\hline Minério de ferro & $706.885,85$ & $837.197,85$ & $806.477,05$ & $837.909,35$ & $973.649,31$ & $1.608 .188,88$ \\
\hline Quartzito & $1.140,83$ & $1.394,76$ & 630,12 & 273,05 & 956,29 & $1.672,13$ \\
\hline
\end{tabular}

Fonte: DNPM, 2010.

${ }^{6}$ É o caso do Município de Diogo de Vasconcelos, que arrecadou apenas R\$71.437, em 2004 (ALMG, 2010). 
normatização do uso do solo na região. Assim tiveram origem algumas Áreas de Proteção Especial (APEs), na década de 1980, e a APA Sul da RMBH e o Parque Estadual da Serra do Rola Moça, na década de 1990 (EUCLYDES, 2009).

Desde então, muitas outras UCs foram ali criadas. É o caso de RPPNs, como a Poço Fundo, das Estações Ecológicas de Fechos e Cercadinho e dos Monumentos Naturais da Serra da Moeda e da Serra do Gambá. Além disso, há uma série de grupos que atualmente reivindicam a criação de áreas protegidas na região, como a Associação Arca-Amaserra, que pleiteia o estabelecimento de uma UC de proteção integral na Serra da Calçada, porção norte da Serra da Moeda, e o grupo de associações que vem demandando a criação do Parque Nacional das Águas do Gandarela, em contraponto a um grande projeto de exploração mineral.

Considerando as atuações desses grupos e a quantidade de UCs ali situadas, o Quadrilátero Ferrífero pode ser caracterizado como o maior foco de tensões entre interesses econômicos e de cunho ambientalista em todo o estado na atualidade. Nesse sentido, a análise da região constitui relevante estudo de caso para a compreensão dos limites e possibilidades das políticas ambientais baseadas em instrumentos econômicos, como o ICMS Ecológico.

Na Tabela 3 apresentam-se os valores recebidos pelos municípios do Quadrilátero Ferrífero referentes ao ICMS Ecológico/UCs, ao ICMS “município minerador” e à CFEM, no primeiro semestre de 2010. Analisando os valores recebidos pelos municípios, alguns números chamam a atenção. Primeiramente, nota-se que, entre os 34 estudados, apenas cinco receberam valores maiores por suas áreas protegidas que por compensação financeira pela exploração mineral em seus territórios. Desses cinco, três não receberam CFEM no período estudado, e os outros dois, Ibirité e Rio Manso, receberam CFEM por substâncias não ferríferas - gnaisse e areia, respectivamente -, além de possuírem UCs que geram importantes arrecadações, como o Parque Estadual da Serra do Rola Moça e a APE Rio Manso.

No que se refere aos diferentes critérios do ICMS, 16 municípios recebem mais pelo ICMS “município minerador” que pelas áreas protegidas. Ou seja, o próprio critério do ICMS repercute na redução do potencial incentivador do ICMS Ecológico/UCs. Note-se também que os cinco maiores arrecadadores no critério relativo à mineração continuaram obtendo, em 2010, significativos faturamentos com essa atividade, já que são também os maiores arrecadadores de CFEM da atualidade no estado.

Sobre essa compensação pela exploração mineral, cumpre destacar que, dos 34 municípios analisados, 15 receberam mais de $\mathrm{R} \$ 1$ milhão nos seis primeiros meses de 2010. Desses 15, um terço se aproximou de R\$10 milhões ou até mais. Trata-se dos Municípios de Nova Lima, Itabira, Mariana, São Gonçalo do Rio Abaixo e Congonhas, tradicionais focos da mineração em Minas Gerais. A CFEM que recebem tem origem principalmente no ferro e no minério de ferro, sendo que, em função da quantidade explorada e do preço do produto, os valores referentes ao ICMS Ecológico/ UCs tornam-se irrisórios. Em São Gonçalo do Rio Abaixo, por exemplo, os valores recebidos a título de CFEM são 4500 vezes maiores que os recebidos através do ICMS Ecológico por suas UCs. Essa razão equivale a 1319, no caso de Itabira, 355, no caso de Nova Lima, 598, no de Mariana, e 749, no caso de Congonhas.

Talvez por motivos como esse, dos cinco municípios citados, apenas Itabira tenha se ocupado em criar unidades de conservação municipais. Nos demais, as UCs existentes foram criadas pela esfera estadual ou por particulares. No quesito UCs, São Gonçalo do Rio Abaixo apresenta a pior situação, contando apenas com a RPPN Comodato Reserva de Peti.

No que se refere à qualidade da conservação realizada nessas UCs, a situação se revela ainda mais delicada - como se apreende da Resolução SEMAD n 1004 , de 2009, que divulga pontuação do Fator de Qualidade referente às UCs. Das 21 UCs que abarcam áreas desses cinco municípios, 10 são RPPNs e duas são APEs, e receberam a pontuação máxima $(1,0)$ no quesito. Cumpre notar que todas as UCs dessas categorias no estado foram avaliadas dessa forma, o que sugere que essas áreas não tenham sido submetidas a avaliações de campo ${ }^{7}$ (MINAS GERAIS, 2009b).

Entre as nove demais, nenhuma recebeu a pontuação máxima, sendo que quatro receberam a pontuação mínima $(0,1)^{8}$. As cinco restantes são: dois parques municipais $(0,5$ e 0,6$)$ e uma reserva biológica municipal $(0,4)$ de Itabira; um parque $(0,8)^{9}$ e uma APA estadual $(0,6)$ de Nova Lima. Essa avaliação sugere 
Tabela 3 - Valores arrecadados pelos municípios do Quadrilátero Ferrífero relativos a ICMS Ecológico/UCs, ICMS “município minerador" e CFEM, no primeiro semestre de 2010.

Table 3 - Figures collected by the municipalities of the Quadrilátero Ferrífero region on the ICMS Ecológico concerning protected areas, ICMS “mining town” and CFEM, between January and June 2010.

\begin{tabular}{|c|c|c|c|}
\hline Município & ICMS UCs & ICMS Mun. Minerador & CFEM \\
\hline Barão de Cocais & 28,99 & $2.417,94$ & $3.243 .186,83$ \\
\hline Belo Horizonte & $33.314,80$ & $17.039,23$ & $57.884,50$ \\
\hline Belo Vale & & $16.099,72$ & $168.172,52$ \\
\hline Betim & $9.411,90$ & $1.763,80$ & $55.019,45$ \\
\hline Brumadinho & $23.268,86$ & $96.433,95$ & $5.715 .898,60$ \\
\hline Caeté & 182,93 & 98,82 & $24.653,10$ \\
\hline Catas Altas & $224.210,83$ & $89.428,13$ & $1.014 .827,99$ \\
\hline Congonhas & $12.967,55$ & $158.228,98$ & $9.722 .774,69$ \\
\hline Conselheiro Lafaiete & $10.749,59$ & $8.952,66$ & $81.782,69$ \\
\hline Ibirité & $79.005,16$ & $2.112,70$ & $62.742,63$ \\
\hline Igarapé & $78.802,73$ & $15.015,75$ & $596.472,85$ \\
\hline Itabira & $11.004,54$ & $564.520,91$ & $14.517 .108,65$ \\
\hline Itabirito & $1.216,41$ & $37.313,01$ & 6.473.136,92 \\
\hline Itatiaiuçu & $51.930,11$ & $45.977,92$ & $2.648 .544,25$ \\
\hline Itaúna & $6.497,77$ & $8.449,82$ & $170.417,62$ \\
\hline Jeceaba & & 30,96 & 34,18 \\
\hline João Monlevade & $47.422,70$ & 878,49 & $70.678,76$ \\
\hline Mariana & $24.141,69$ & $203.653,99$ & $14.454 .547,88$ \\
\hline Mario Campos & 824,06 & & \\
\hline Mateus Leme & $51.454,66$ & $11.209,48$ & $1.047 .475,92$ \\
\hline \multicolumn{4}{|l|}{ Moeda } \\
\hline Nova Lima & $45.049,90$ & $261.380,26$ & $15.998 .864,66$ \\
\hline Ouro Branco & $26.292,06$ & 60,12 & \\
\hline Ouro Preto & $20.818,61$ & $169.042,70$ & $4.721 .461,65$ \\
\hline Raposos & $1.392,18$ & $7.027,40$ & \\
\hline Rio Acima & $2.299,08$ & 231,10 & $124.824,96$ \\
\hline Rio Manso & $101.043,70$ & & 299,92 \\
\hline Rio Piracicaba & $4.765,55$ & $10.326,87$ & $1.128 .076,63$ \\
\hline Sabará & 340,09 & $27.830,13$ & $2.180 .348,81$ \\
\hline Santa Bárbara & $59.670,31$ & $73.033,71$ & $1.209 .990,86$ \\
\hline Santa Luzia & 504,72 & 33,66 & $70.671,12$ \\
\hline São Gonçalo do Rio Abaixo & $2.406,71$ & $24.294,85$ & $11.018 .687,91$ \\
\hline São Joaquim de Bicas & $2.794,94$ & & $472.620,25$ \\
\hline Sarzedo & $2.462,96$ & & $121.303,71$ \\
\hline
\end{tabular}

Fonte: FJP, 2010; DNPM, 2010.

\footnotetext{
${ }^{7}$ Sobre a possível não avaliação em campo dessas UCs é preciso tecer algumas observações. No caso das RPPNs, apesar de contribuírem para o sucesso da conservação ambiental, na medida em que podem ser implantadas em parceria entre o governo e as organizações privadas para fortalecer zonas de amortecimento, por exemplo (SCHIAVETTI et al., 2010), há também UCs dessa categoria criadas por empresas, que necessitam ser fiscalizadas para assegurar o adequado cumprimento dessa compensação. Já no caso das APEs existentes em Minas Gerais, há indícios de que o Estado tenha pouco controle sobre as atividades que ali tomam lugar, como verificado por Euclydes (2009), o que reitera a necessidade da fiscalização dessas áreas).

${ }^{8}$ Entre as UCs avaliadas com o fator 0,1 está a Estação Ecológica de Fechos, em Nova Lima, considerada como possuindo "efetividade de manejo insatisfatória" no estudo empreendido por Lima et al. (2005), que avaliou fatores como demarcação da área, desapropriações, recursos humanos, infraestrutura, relação com o entorno, entre outros.

${ }^{9}$ Segundo o citado estudo de Lima et al. (2005), o Parque Estadual da Serra do Rola Moça foi avaliado como de "efetividade de manejo média".

${ }^{10}$ Essa taxa seria paga pelo consumidor no ato da aquisição de combustíveis de origem fóssil, devendo o produto de sua arrecadação ser investido na conversão, para vegetação nativa, de áreas necessárias à proteção dos recursos hídricos, à recarga de aquíferos e à proteção da biodiversidade, submetidas a uso alternativo de solo.
} 
que esses municípios, embora disponham de recursos, não estejam investindo significativamente nas UCs situadas em seus territórios.

Assim, percebe-se que o ICMS Ecológico tem sido de pouca eficiência no incentivo à criação, à ampliação de áreas de proteção e ao empenho na qualidade da conservação ambiental nos municípios mineradores do estado.

\section{DISCUSSÕES}

Os instrumentos econômicos de gestão ambiental podem ser vistos como uma inversão da lógica da política ambiental baseada em mecanismos de comando e controle: a ênfase das ações do poder público deixa de ser a multa imposta ao proprietário que desmata indevidamente suas terras e se volta para o incentivo àquele que protege áreas além do mínimo previsto em lei. Porém, tais instrumentos podem também ser vistos como formas de pagamento pela degradação ambiental, como no projeto de taxa de proteção ambiental que tramitou na Assembleia Legislativa do Estado de Minas Gerais entre os anos de 2009 e $2010^{10}$. Podem, ainda, ser considerados indevidos, como no caso do ICMS Ecológico referente aos sistemas de saneamento ambiental, que paga aos municípios para que instalem sistemas que já constam de suas obrigações previstas por lei.

No presente artigo, demonstrou-se a reduzida expressividade de um desses instrumentos: o subcritério “unidades de conservação” do ICMS Ecológico mineiro. Analisando os valores recebidos pelas UCs de Nova Lima, observou-se que, muitas vezes, os valores pagos por área protegida são muito pouco significativos. Quando esses dados foram comparados aos defasados valores recebidos por meio do critério "município minerador”, verificou-se que a função incentivadora do ICMS Ecológico/UCs é sensivelmente limitada, já que muitos municípios recebem mais pela atividade mineradora que realizavam na década de 1980 que pela proteção ambiental que se dá em seus territórios nos dias de hoje.

Na análise detida dos municípios do Quadrilátero Ferrífero, constatou-se um cenário ainda mais discrepante. Os valores relativos à CFEM recebidos por esses municípios chegam a ser centenas de vezes maiores que os pertinentes ao ICMS Ecológico/UCs.

Certamente, a escolha dos municípios mineradores como recorte espacial de estudo levou a esses resultados tão destoantes. É possível que, trabalhando com dados de uma região onde a mineração não se volte para substâncias tão valorizadas, encontremos diferenças menores entre os critérios "unidades de conservação" e “município minerador” do ICMS e a CFEM. Porém, para os municípios analisados, de fato, o ICMS não representa um incentivo relevante para a proteção ambiental, o que se confirma nos casos dos maiores arrecadadores de CFEM, que pouco investiram na criação de áreas protegidas municipais ou na manutenção das UCs criadas pelo estado.

A análise dos dados referentes aos municípios do Quadrilátero Ferrífero indicou que o incentivo à proteção ambiental via ICMS Ecológico só se faz relevante economicamente para os cofres públicos nos municípios onde a exploração mineral não tem expressão econômica considerável.

Essa constatação vai de encontro à fragilidade dos ambientes da região, considerados de suma importância ecológica, em função de sua geomorfologia e de sua biogeografia. Nessa região, riqueza ecológica e riqueza mineral coincidem espacialmente, o que limita a possibilidade da convivência da atividade extrativa mineral com a conservação da biodiversidade, motivo pelo qual ali ocorrem significativos conflitos entre os interesses da indústria mineral e os movimentos ambientalistas.

Nesses conflitos, além de se valer do argumento de que proporcionará desenvolvimento econômico e geração de empregos, a indústria mineral tem a seu favor a CFEM, que pode multiplicar a arrecadação municipal, o que tende a angariar a simpatia dos governos locais. De outro lado, os movimentos ambientalistas contam apenas com o apelo ao senso ecológico da população e ao fato de que a exploração mineral da região pode comprometer o abastecimento de água da região metropolitana, que depende dos mananciais ali situados. Desse modo, esses conflitos são marcados pela desigualdade entre os atores, o que potencializa os prejuízos à biodiversidade.

\section{CONCLUSÃO}

O que poderia ser feito para aprimorar os instrumentos econômicos mencionados? Uma possível alternativa seria o estabelecimento de mais uma variável no cálculo do ICMS Ecológico/UCs, que considerasse a fragilidade e a importância ecológica dos ecossistemas, de modo a incentivar a proteção de determinados ambientes. 
Conforme a importância ecológica da região, uma UC seria melhor classificada, o que repercutiria em maiores incentivos à criação de áreas protegidas.

Porém, mesmo essa alternativa é limitada, já que o valor total do ICMS Ecológico se mantém em 1,1\%, independentemente de haver 10 ou 10.000 UCs no estado. Ou seja, quanto mais áreas protegidas houver, mais esse valor se diluirá e representará cada vez menos retorno financeiro aos municípios. Assim, a tendência é que a função incentivadora desse tributo seja cada vez menos expressiva. Tendo isso em conta, pode-se propor que essa alíquota seja progressivamente aumentada - apropriando-se, inclusive, dos 0,01\% destinados ao critério "município minerador", que poderia ser extinto, dada a existência da CFEM.

Por fim, outra proposta, que não exclui as anteriores, seria a vinculação ${ }^{11}$ da aplicação de parte dos recursos obtidos com a CFEM a projetos de educação e proteção ambiental, inclusive de cunho turístico.

Os instrumentos econômicos da política ambiental brasileira e mineira ainda estão em consolidação, e, para que se efetivem repercutindo na progressiva proteção dos ecossistemas, é preciso realizar importantes ajustes. Com as críticas e propostas aqui apresentadas, acredita-se contribuir para esse aprimoramento, que deve buscar tornar os incentivos à proteção ambiental robustos o suficiente para fazer frente às diversas formas de fomento existentes para a produção mineral e à compensação pela exploração mineral. Sem esses ajustes, não há que falar em função incentivadora do ICMS Ecológico para os municípios do Quadrilátero Ferrífero, e essa região, de grande importância biológica, permanecerá na situação em que se encontra hoje: tendo sua conservação dependente de iniciativas de particulares ou da esfera estadual.

\section{REFERÊNCIAS}

\section{ASSEMBLEIA LEGISLATIVA DO ESTADO DE} MINAS GERAIS - ALMG. O Estado.

Disponível em: <www.almg.gov.br> Acesso em: 12 set. 2010.
BENSUSAN, N. ICMS ecológico: um incentivo fiscal para a conservação da biodiversidade. In: BENSUSAN, N. (Org.). Seria melhor mandar ladrilhar? Biodiversidade como, para que, por quê. Brasília: UNB, 2002.

\section{BRANDT MEIO AMBIENTE. Patrimônio natural, cultural e zoneamento ecológico-econômico da Serra da} Moeda: uma contribuição para sua conservação. Belo Horizonte: Sindiextra/Fiemg, 2008.

BRASIL. Constituição da República Federativa do Brasil de 1988. Disponível em: <http:// www.planalto.gov.br/ccivil_03/constituicao/ ConstituicaoCompilado.htm> Acesso em: 20 out. 2010.

BRASIL. Lei $n^{0} \mathbf{8 . 0 0 1}$, de 13 de março de 1990. Define os percentuais da distribuição da compensação financeira de que trata a Lei ${ }^{\circ}$ 7.990, de 28 de dezembro de 1989, e dá outras providências. Disponível em: <http:// www.planalto.gov.br/ccivil_03/Leis/L8001. htm\#art3> Acesso em 21 dez. 2010.

COSTA, C. M. R. et al. (Org.). Biodiversidade em Minas Gerais: um atlas para sua conservação. Belo Horizonte: Fundação Biodiversitas, 1998.

DEPARTAMENTO NACIONAL DE PRODUÇÃO MINERAL - DNPM. CFEM. Brasília: 2010. Disponível em: <http://www.dnpm.gov.br> Acesso 30 jul. 2010.

EUClydes, A. C. P. APEs/Áreas da Copasa. O que há de especial na proteção dos mananciais?: Um estudo sobre as Áreas de Proteção Especial - APEs - do Eixo Sul da Região Metropolitana de Belo Horizonte. 2009. Monografia (Graduação em Geografia) Universidade Federal de Minas Gerais, Belo Horizonte, 2009.

FUNDAÇÃO JOÃO PINHEIRO - FJP. Lei Robin Hood. Belo Horizonte: 2010. Disponível em: $<$ http://www.fjp.gov.br/produtos/cees/ robin_hood>.Acesso: 30 jul. 2010.

\footnotetext{
${ }^{11}$ A Lei Federal nº 8.001, de 13 de março de 1990, que define os percentuais da distribuição da compensação financeira de que trata a Lei $n^{\circ} 7.990$, de 28 de dezembro de 1989, e dá outras providências, apenas veda a aplicação dos recursos em pagamento de dívida e no quadro permanente de pessoal, não estipulando setores em que esses valores devem necessariamente ser aplicados.
}

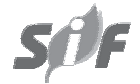


FREITAS, E. S. M. A Reprodução Social da Metrópole em Belo Horizonte: APA Sul $\mathrm{RMBH}$, mapeando novas raridades. 2004. Dissertação (Mestrado em Geografia) - Universidade Federal de Minas Gerais, Belo Horizonte, 2004.

LIMA, G. S.; RIBEIRO, G. A.; GONÇALVES, W. Avaliação da efetividade de manejo das unidades de conservação de proteção integral em Minas Gerais.

Revista Árvore, v.29, n.4, p.647-653, 2005.

LOUREIRO, W. ICMS ecológico: a consolidação de uma experiência brasileira de incentivo à conservação da biodiversidade. In: CONGRESSO BRASILEIRO DE UNIDADES DE CONSERVAÇÃO, 3., 2002, Fortaleza. Anais... Fortaleza: Rede PróUnidades de Conservação, 2002.

MINAS GERAIS. Decreto $n^{\circ} 32.771$, de 4 de julho de 1991. Dispõe sobre a apuração do valor adicionado, para efeito de repasse, aos municípios, da parcela que lhes couber na arrecadação do ICMS, e dá outras providências. Diário Oficial, Belo Horizonte, 5 jul. 1991. p.4.

MINAS GERAIS. Lei n 12.040 , de 28 de dezembro de 1995. Dispõe sobre a distribuição da parcela de receita do produto da arrecadação do ICMS pertencente aos Municípios, de que trata o inciso II do parágrafo único do artigo 158 da Constituição Federal, e dá outras providências. Diário Oficial, Belo Horizonte, 29 dez 1995. p.1.
MINAS GERAIS. 2009a. Lei $\mathbf{n}^{\circ}$ 18.030, de 12 de janeiro de 2009. Dispõe sobre a distribuição da parcela da receita do produto da arrecadação do ICMS pertencente aos Municípios. Diário do Executivo, Belo Horizonte, 13 jan. 2009, p.3.

MINAS GERAIS. 2009b. Secretaria de Estado de Meio Ambiente e Desenvolvimento Sustentável SEMAD. Resolução SEMAD n ${ }^{0} 1.004$, de 27 de julho de 2009. Divulga pontuação final do Fator de Qualidade referente às Unidades de Conservação da Natureza e outras Áreas Especialmente Protegidas, conforme estabelecido na Deliberação Normativa COPAM n ${ }^{\circ} 86$, de 17 de julho de 2005, e dá outras providências. Diário do Executivo, Belo Horizonte, 28 jul. 2009. Disponível em: <http://www.siam.mg.gov.br/sla/

download.pdf?idNorma=9911 > Acesso em: 20 ago. 2011.

SCHIAVETTI, A. et al. Análise das reservas particulares do patrimônio natural como estratégia de conservação na região cacaueira do Sul da Bahia, Brasil. Revista Árvore, v.34, n.4, p.699-711, 2010.

UNIVERSIDADE FEDERAL DE OURO PRETO UFOP. Centro de Estudos Avançados do Quadrilátero Ferrífero. Estudos geoambientais. Disponível em: <www.qfe2050.ufop.br> Acesso em: 12 out. 2010. 